\title{
RESEÑA
}

\section{Ernesto Osorno Mesa 1904 - 1976}

\author{
Alberto Morales
}

\begin{abstract}
El 28 de junio de 1976 falleció en Bogotá, Colombia, lugar donde había nacido, el profesor Ernesto Osorno Mesa, médico parasitólogo y entomólogo, quien ha sido considerado, sin duda alguna, el fundador de los estudios de entomología médica en Colombia.
\end{abstract}

En 1927 terminó sus estudios en la Facultad de Medicina de la Universidad Nacional de Bogotá e ingresó como interno al Hospital San José de la misma ciudad, donde laboró por espacio de dos años. Su temprano interés por las ciencias naturales y la medicina tropical hizo que, ya en 1926, fuera elegido miembro de la Sociedad de Medicina Tropical y de la Sociedad Colombiana de Ciencias Naturales y, en 1929, profesor de historia natural en el Gimnasio Moderno de Bogotá. De 1929 a 1933, desempeñó el cargo de jefe del Laboratorio de Fisiología de la Facultad de Medicina de Bogotá.

Posteriormente ocupó la posición de médico jefe de las comisiones sanitarias antianémicas en los departamentos del Valle, Caldas y Cundinamarca, cargo que desempeñó en 1933 y 1934. Fue, precisamente, en desarrollo de esta labor que realizó su tesis para optar al doctorado de medicina y cirugía, la cual tituló Criterio moderno sobre campañas contra uncinaria y otros parásitos intestinales, la cual fue galardonada con mención honorífica; esta investigación la llevó a cabo en la población de Bolívar, departamento del Valle, la cual realizó con el rigor científico y el análisis crítico que caracterizó toda su labor investigativa. Hoy, siguen siendo perfectamente válidos sus conceptos de ese entonces acerca de que el tratamiento de una enfermedad transmisible es

Investigador emérito, Laboratorio de Entomología, Instituto Nacional de Salud secundario ante "la labor primaria, inaplazable e insustituible" de la prevención, pero que cualquier esfuerzo en este último sentido es muy difícil o casi imposible si al pueblo no se le educa; no es sino recorrer las páginas de su tesis para enterarse de la tremenda lucha que tuvo que librar para poder vencer, siquiera en mínima parte, tanta incomprensión y prejuicios nacidos de la ignorancia.

En su tesis de grado, hace, además, referencia a algunos artrópodos encontrados y determinados por él en el municipio de Bolívar (Valle), siendo ésta una de sus primeras contribuciones al estudio de los artrópodos que afectan la salud del hombre en nuestro país. Desde

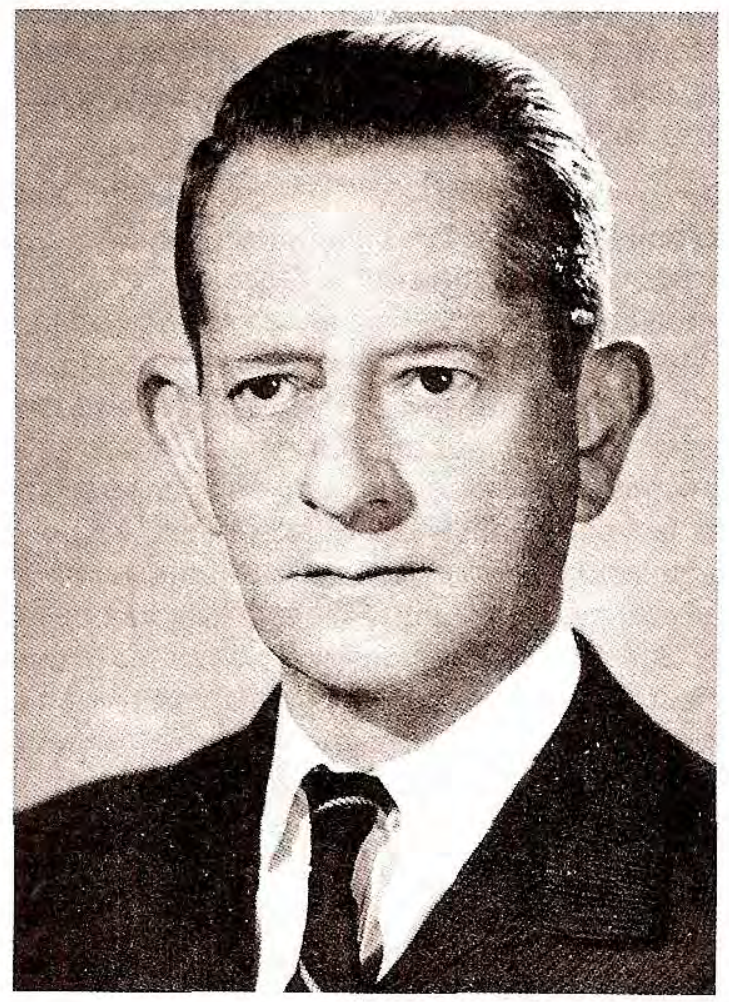


entonces, todo su empeño y capacidad a lo largo de su meritoria existencia estuvieron dedicados a la investigación y a la enseñanza en el campo de los vectores de enfermedades metaxénicas del hombre y los animales.

En el año de 1935, ingresó como médico entomólogo a la Sección de Estudios Especiales del Ministerio de Trabajo, Higiene y Previsión Social, y los próximos dos años, 1936 y 1937, los dedicó a especializarse en entomologia médica en Ithaca, N. Y., y en la Universidad de Harvard en Boston, Estados Unidos, bajo la dirección del profesor Joseph C. Bequarert. A su regreso de los Estados Unidos, se reincorporó a sus tareas de investigación en entomología médica en el Instituto Carlos Finlay, institución a la que estaría vinculado ininterrumpidamente hasta el año 1947. Su paso por este instituto, al lado de eminentes investigadores nacionales y foráneos, marca uno de los hitos en la investigación médica en Colombia.

Gran parte de la actividad científica del doctor Osorno durante estos años la orientó hacia el estudio de los mosquitos del género Haemagogus por encontrarse dentro de este género algunas especies vectoras eficientes del virus de la fiebre amarilla selvática.

Como se recordará, en 1907, los investigadores colombianos doctores Roberto Franco, Jorge Martínez Santamaría y Gabriel Toro Villa estudiaron una epidemia en las minas de Muzo (Boyacá), que ellos diagnosticaron compuestas por fiebre amarilla y fiebre espiroquetal, asociadas, y en sus conclusiones afirmaron que la fiebre amarilla era contraida en el bosque y no en la vecindad de las habitaciones y que la inoculación del virus se hacía durante las horas del día, que son las que los trabajadores pasan en donde predominan los mosquitos transmisores. Lo importante de sus conclusiones estriba en que en esa época no se concebía fiebre amarilla sin Aedes aegypti, es decir, se conocía únicamente el ciclo urbano de la fiebre amarilla y estos investigadores enunciaron la teoría, completamente revolucionaria para la época, que existía un ciclo selvático de la enfermedad. Estas admirables conclusiones fueron confirmadas años más tarde, tanto en Colombia como en Brasil, y poco después de que se detectaran los primeros casos de fiebre amarilla selvática en las cercanías de la población de Restrepo (Meta) por el doctor Jorge Boshell-Manrique a fines de 1934. El doctor Osorno empezó a colaborar en la investigación de los reservorios y vectores silvestres de la modalidad selvática de este virus al lado del mismo doctor J. Boshell, del entomólogo brasilero P. A. Antunes y J. C. Bugher.

En 1944 apareció publicado en el American Journal of Hygiene un artículo firmado por J. C. Bugher, J. Boshell-Manrique, M. Roca-García y E. Osorno-Mesa, acerca de la epidemología de la fiebre amarilla selvática en los Llanos Orientales de Colombia, en donde se informa del aislamiento del virus en condiciones naturales a partir de mosquitos Haemagogus capricornii (hoy sabemos que se trata de Haemagogus janthinomys) y, además, se decriben los hábitos de esta especie de mosquito; por primera vez, se conoce que los Haemagogus son mosquitos arbóreos, hecho de capital importancia que viene a explicar el mecanismo de transmisión del virus de la fiebre amarilla selvática a monos en el follaje de los árboles. Los trabajos de Osorno, Boshell y otros investigadores en los Llanos Orientales y otras regiones de Colombia contribuyeron a develar muchas de las incógnitas acerca de la historia natural del virus amarílico selvático (reservorios, vectores, etc.).

Una vez demostrada la importancia de los mosquitos del género Haemagogus en la transmisión del virus, el doctor Osorno continúa sus estudios fundamentales en este campo. Describe dos nuevas especies, Haemagogus andinus, encontrada en el municipio de Fusagasugá (Cundinamarca) y Haemagogus boshelli de la costa del Pacífico, establece colonias de Haemagogus equinus y Haemagogus splendens, demuestra la transmisión en el laboratorio del virus de la fiebre amarilla por Haemagogus splendens (ahora llamado $H$. celeste) y publica con H. W. Kumm y J. 
Boshell-Manrique un trabajo sobre la distribución geográfica conocida hasta entonces de las ocho especies de Haemagogus que se sabe existen en Colombia.

A finales de 1947, el profesor Osorno pasó a ocupar el cargo de médico jefe del Laboratorio de Entomología de la División de Malariología del Servicio Cooperativo Interamericano de Salud Pública, posición que desempeñó hasta comienzos de 1950, cuando fue nombrado director interino de la División de Malariología.

Durante este período, contribuyó de manera decisiva al conocimiento de las especies de Anopheles de Colombia y a desarrollar técnicas que facilitaran la búsqueda de esporozoítos de Plasmodium en humanos que permitieran determinar con mayor facilidad las especies vectoras. Describió una nueva especie, Anopheles oiketorakras, la cual encontró en la hoya hidrográfica del río San Francisco, al oriente de Bogotá, a alturas entre 2.700 y 2.840 m sobre el nivel del mar e hizo, además, una excelente reseña sobre su ecología. Con doña Fenita Muñoz de Osorno describió una nueva variedad de Anopheles, Anopheles pseudopunctipennis bifoliata. Desarrolló nuevas técnicas para el estudio de los huevos de Anopheles y para "disectar glándulas salivales y estómagos de mosquitos y determinar oocistos de Plasmodium en ejemplares infestados en condiciones naturales".

Fué, el profesor Osorno, el fundador de la cátedra de entomología en la Facultad de Medicina de la Universidad Javeriana en Bogotá, al frente de la cual estuvo de 1944 a 1967, y profesor de biología y parasitología en la Facultad de Medicina de la Universidad Nacional en Bogotá desde 1951 hasta 1963. Su labor en la enseñanza de la parasitología y la entomología médica fue una de sus contribuciones más fecundas al desarrollo del conocimiento de los insectos vectores de enfermedades en Colombia. Como buen maestro que era, consideraba que se podía hacer buena investigación sin docencia pero que no se podía concebir a un buen docente que no realizara investigación. Siempre criticó, con sobrada razón, el hecho de que nuestras facultades de medicina y escuelas de salud pública no contaran con departamentos de entomología médica.

En el año de 1964, ingresó como jefe del Subgrupo de Entomología al Instituto Nacional de Salud y, entonces, decidió que era necesario hacer un estudio de la fauna de flebotomíneos, Lutzomyia (Diptera-Psychodidae) de Colombia, grupo de insectos de importancia en la transmisión de leishmaniasis cutánea y visceral y bartonelosis, de los cuales se tenía entonces, en nuestro país, una muy deficiente información. Previamente a sus trabajos sobre este tema, sólo se había señalado cerca de una veintena de especies para el país, la mayor parte de las cuales fueron halladas con ocasión de las investigaciones realizadas acerca de la grave epidemia de bartonelosis que ocurrió a finales de la década de 1930 y comienzos de la de 1940 en Cauca y Nariño, y en cuyo estudio intervino el mismo doctor Osorno.

Los resultados de su trabajo con los flebotomíneos de Colombia se pueden sintetizar diciendo que describió como autor o coautor 9 nuevas especies de Lutzomyia e incrementó en varias decenas los nuevos registros de especies para el país; desarrolló una nueva técnica para el montaje y coloración de las finas estructuras de estos insectos y reunió una excelente colección de referencia.

Pero, además de las investigaciones que hemos reseñado, el profesor Osorno hizo importantes contribuciones al conocimiento de la ecología y taxonomía de los Bombidae, los lagartos del género Phenacosaurus y Leiocephalus, y realizó el mejor estudio que hasta ahora haya sido hecho de las garrapatas de Colombia; fue coautor de la publicación en que se comunicaba el primer hallazgo en el país de miasis uterina por Callitroga americana. Se interesó por el estudio de los reservorios y vectores de la enfermedad de Chagas y con Andrés Soriano Lleras publicó un bien documentado y ameno trabajo sobre Datos históricos de observaciones hechas en Colombia sobre artrópodos molestos y patógenos para el hombre. 
Asistió a numerosos congresos en donde presentó muchos de los resultados de sus investigaciones; perteneció a varias sociedades científicas: miembro de la American Mosquito Control Association, miembro de número de la Academia Colombiana de Ciencias Exactas, Físicas y Naturales, miembro correspondiente de la Academia Nacional de Medicina, miembro fundador de la Sociedad Colombiana de Parasitología y Medicina Tropical, miembro honorario de la Sociedad Colombiana de Patología.

Fue galardonado con la medalla cívica de mérito asistencial Jorge Bejarano, con el premio Karl von Linne de entomología de la Fundación Camilo Mutis Daza en 1968 y el Premio Caldas de Ciencias de 1972.

El profesor Osorno se jubiló en el año de 1970 , lo cual no significó que abandonara la investigación científica, pues, continuó como consejero ad honorem en el Subgrupo de Entomología del Instituto Nacional de Salud hasta el día de su muerte.

Conoció y amó a su país intensamente; fue un hombre de carácter con un fino sentido del humor, investigador científico y maestro en I más excelso sentido del vocablo. 